\title{
Hans Bethe and the Global Energy Problems.
}

\author{
Boris Ioffe \\ Institute of Theoretical and Experimental Physics, \\ B.Cheremushkinskaya 25, 117218 Moscow,Russia
}

\begin{abstract}
Bethe's view-point on the global energy problems is presented. Bethe claimed that the nuclear power is a necessity in future. Nuclear energetic must be based on breeder reactors. Bethe considered the non-proliferation of nuclear weapons as the main problem of long-range future of nuclear energetics. The solution of this problem he saw in heavy water moderated thermal breeders, using uranium-233, uranium-238 and thorium as a fuel.
\end{abstract}

\section{My contacts with Bethe.}

I heard Bethe's name first time in 1947. I was the student of the 3rd course of the physical faculty of Moscow University. I was not satisfyed by the level of education there, especially by the teaching of theoretical physics - all the best russian theoreticians Landau, Tamm, Leontovich and others were expelled from the University, because they did not share the official points of view of Marxist philosophy. After some doubts - if I am able to be a theoretical physicist or not - I decided to try to give up to Landau his theoretical minimum. I passed successfully the first entering exam on mathematics and Landau gave me the program of the whole minimum. That time among now well known Landau Course of Theoretical Physics only $3 \frac{1}{2}$ books were published: Mechanics, Classical Field Theory, Mechanics of Condensed Matter and the fist part of Statistics (Classical Statistics). All other parts of the Course the student should study mostly by reading original papers, which were in German and English. (It was implicitly assumed that the student fluently knows both languages - a very nontrivial case at that time.) In the program of Quantum Mechanics there were 3 papers of H.Bethe: the theory of atomic levels in the fields of crystall [1]; the theory of collisions of fast electrons with atoms 2]; the theory of deuteron [3]. Especially, it was very hard to study the first and the second papers - about 75 pages each in German, the language, which I learned only being a boy and almost forget and with enormous amount of complicated calculations. I repeated all of them! Just starting from this moment I have a great respect to Bethe. 
When I passed all Landau examinations, became a member of Landau seminar and met Landau very often, as a rule 2-3 times a week, I realized that he also has a great respect to Bethe. He called him every time - Hans Albrecht, not by the last name (Pomeranchuk called Bethe in the same way.) The comparison with Bethe results was the highest estimation by Landau.

I would like to tell also about the indirect connection of our work with one Bethe remark, now almost forgotten. In 1951 the Pomeranchuk group at ITEP, in which I participated, started to work on the project of hydrogen bomb, called "Tube" (Truba). This was the continuation of the work, performed earlier by Zeldovich and Landau groups. In US a similar project was developed by Teller and was known as "Classical Super". In short the idea of the project was the following. A long cylinder is filled by liquid deuterium. At one end of the cylinder the atomic bomb and the intermediate device filled by deuterium and tritium are situated. It was expected, that after atomic bomb explosion the fusion reaction will start in $D+T$ mixture, resulting in high temperatures and the shock wave will propagate along the cylinder, inducing $D+D$ fusion with the explosion (in principle) of unlimited power for a long enough tube. The essential step in the project was the calculation of energy balance. The main source of energy loss was the bremsstrahlung - production of $\gamma$-rays in electron - ion collisions, since $\gamma$-rays leave the system. In course of propagation in the cylinder, $\gamma$-rays undergo Compton scattering. Because the bremsstrahlung spectrum is softer, than the electron spectrum, the energy of $\gamma$ 's increases at Compton scattering. (Sometime this process is called inverse Compton scattering.) The calculation of this increasing of energy loss due to Compton scattering and the calculation of the energy balance with account of this effect was the main task of the Pomeranchuk group with collaboration with the Zeldovich group. Much later, I read in 4], that at the conference at Los Alamos in April 1946, where Teller presented the results of his calculations of Classical Super, Bethe made a remark, that the account of inverse Compton scattering of $\gamma$ 's (not accounted by Teller), will result in negative energy balance and that the hydrogen bomb of this type will not explode. In our calculations after hard work we came to the same conclusion - the energy balance was negative. Bethe intuitive prediction was marvelous! (This story is described in more details in [5, [6].) E.Teller and his group came to the similar conclusion.

I met Hans the first time in 1994, when he visited ITEP. He was invited into ITEP Director office, where were also few ITEP physicists, including myself. According to the standard procedure, ITEP Director Prof.I.V.Chuvilo told to the guest about the main investigations proceeding in the Institute, and suggested the program of his visit: to see first this installation, then that and so on. But Bethe refused to follow this program - he said: I would like to have a conversation with ITEP theoreticians and first of all I would like to know, what they are doing in QCD. So, we went to my office and for about two hours, I explained Hans our results in QCD: the calculations of baryon masses, based on the leading role of spontaneous violation of chiral symmetry in QCD vacuum, the calculations of baryon magnetic moments etc. Hans listened very attentively, put questions and it was clear, that he would like to understand the subject completely. Only one time, after about 1 hour of conversation he said: I would like to rest for 10 minutes. I left the room, came back in 10 minutes and the conversation was continuing. (Hans was 87 at that time!) 


\section{The necessity of nuclear power.}

Bethe interest to nuclear power arises naturally, since starting from 30-ies he became one of the best specialists in nuclear physics. It is enough to recall his reviews on theoretical nuclear dynamics [7], his paper on diffraction scattering of nucleons on nuclei [8] his lectures on nuclear theory 9]. In 1942-1946 Bethe was the Head of Theoretical Division at Los Alamos. In 1956-1957 Bethe participated in experimental work, where the inelastic cross sections of fission spectrum neutrons were measured on various elements [10]. These data are important for construction of power nuclear reactors, especially of the breeders on fast neutrons.

Starting from 70-ies Bethe was greatly concerned over global energy problems - over the balance of energy production and consumption in the world in future. In two papers [1], 12 published in 1976,1977 he discussed these problems. Bethe expected that the consumption of energy will steadily increase in next decades, but the production of oil, the main source of energy, will drop around the year 2000 and the oil (and gas) prices will jump up. Now we know, that his prediction about rising of oil and gas prices was correct and also, what he did not discussed, few developing countries, like China, India, Brasil are joining now the club of main energy consumers. Bethe considered two ways to avoid the future energy crises.

The first one was the energy conservation - the improving the efficiency with which the energy is consumed. He stressed the necessity of great efforts towards energy conservation: besides the technical and industrial progress, public education and tax or other incentives are needed [10]. However, in this way only a temporary solution (for the next 10-20 years) of the problem may be achieved: in the long range perspective the energy conservation will not help very much.

The second way is the intensive use of new sources of energy. Among these coal, nuclear fusion and solar power were considered. Bethe was sceptical about the extensive use of coal, especially in Europe, where the coal resources are restricted and deep mining is needed. The use of nuclear fusion requires the solution of many hard engineering problems. So, Bethe expected [11, that, in the best case, fusion might contribute only few percent of USA's power supply not to early as in 2020. The solar power was considered in more details in [10] and the conclusion was: solar power is likely to remain extremely expensive in USA, Europe and Japan, but "it might be just the right thing for certain developing countries, which have large desert areas and rather modest total energy needs". Bethe concludes, that all alternative sources of energy, including wind, biological sources, should be investigated and developed, but they cannot solve the future energy problems.

The final conclusion was: there is no alternative to nuclear power. "The nuclear power is a necessity not merely an option. A necessity if we want to make a smooth transition from our present oil- and gas-based economies to the post-oil world" [12]. 


\section{The advantages and problems of nuclear energet- ics.}

Bethe emphasized that the main problem of long-range future of nuclear energetics based on breeder reactors is the problem, how to provide the non-proliferation of nuclear weapons. He shared the point [13], that this goal cannot be achieved, if the facilities, where plutonium or weapon-grade uranium are produced, like reprocessing or isotope separation plants, would be widely distributed over the world. Bethe believed, that the wide spread of nuclear energetics may be reconciled with non-proliferation of nuclear weapons, if the fuel for nuclear reactors will be not only uranium, but also thorium. He supported the proposal by T.B.Taylor and H.A.Feiverson [13] as a possible scheme of future nuclear energetics. According to it the nuclear power plants should be of two types. The first type are the power plants with thermal reactors using ${ }^{233} U,{ }^{238} U$ and thorium as a fuel. The moderator in such reactors should be heavy water. As the most perspective heavy water reactors. Bethe considered Canadian reactors CANDU ${ }^{1}$ Then one may expect a high, close to 1 conversion coefficient (the ratio of new formed fission elements $-{ }^{233} U$ and ${ }^{239} \mathrm{Pu},{ }^{241} \mathrm{Pu}$ to the burned ones). The ratio of ${ }^{233} \mathrm{U}$ to ${ }^{238} \mathrm{U}$ must be chosen in such a way, that after chemical separation of uranium, it will not be suitable for nuclear weapons. Also, the concentration of plutonium should be much smaller than those of ${ }^{233} U$. The nuclear power plants of the second type are the plants with breeder reactors on ${ }^{238} U$ and plutonium. The blankets of breeders would be made of thorium so as to produce ${ }^{233} U$ for thermal reactors. The plutonium produced in thermal reactors would be fed back to breeder reactors. The number of fast breeders should be much smaller, than the number of thermal reactors.

The problem of nonproliferation of nuclear weapons is weaker in the proposed by Bethe two-component scheme of nuclear energy plants, than in case of energy production by fast breeder reactors. The number of breeder reactors in two-components scheme is relatively small, they should be under international management and located in countries of the great internal stability. The plants for reprocessing breeder blanket should be located in close proximity to them. Only the thermal reactors would be sold in international trade. Of course, as mentioned by Bethe, to in order prevent proliferation, some international agreement is necessary and, therefore, some restrictions to national sovereignty. But this is the price for the world peace.

Bethe expected that nuclear energetics formed in this way will cover all energy consumption of the world for many thousand years and electric energy, produced on nuclear power stations will be cheaper, than those produced on the stations using fossil fuel. (It must be mentioned that the last conclusion was based on the economical calculations performed before Three Mile Island and Chernobyl accidents. After that the requirements to the safety on nuclear power stations strenghtened, essentially in USA, what resulted

\footnotetext{
${ }^{1}$ In 1995 I participated at E.Wigner Memorial Meeting of APS, where Bethe presented his recollections on Wigner. There was also a talk "Wigner as nuclear engineer" given by Alvin Weinberg. After this talk I give a remark about the development of nuclear reactors theory in the USSR (stressing that it was independent from those un US) and about construction of heavy water reactors in USSR. After the Meeting I had a conversation with Bethe - he did not know about heavy water reactors in the USSR. (The description of the development of heavy water reactors in USSR is given in [14]).
} 
in three times increasing of their costs in USA. At the same time the price of fossil fuel also increased. So, new economical analysis must be used now.) In carrying out this program the problems of chemical separation of the fuel containing thorium, uranium and plutonium as well as engineering problems must be solved. One of the most hard technical problems is the problem of remote handling of the fuel. The reason is that in the fuel, containing ${ }^{233} U$ in the reactor core, due to $(n, 2 n)$ reaction by fast neutrons ${ }^{232} U$ is formed and the products of radiative chain, started from ${ }^{232} U$, are highly radioactive. But, on the other side, the same circumstance provides the protection against theft.

The other serious problems arising from wide use of nuclear energetics are: the problem of waste disposal, and the release of radioactivity by nuclear power stations, especially in case of fatal accidents on nuclear reactors.

In discussion of the problems of wast disposal Bethe refers to the Report to the American Physical Society by the Study Group on Nuclear Fuel Cycles and Waste Management (APS Study Group) [15]. He cites the general conclusion of the Report: "Effective long-term isolation for spent fuel, high-level or transuranic wastes can be achieved by geological emplacement ... Many waste repository sites with satisfactory hydrogeology can be identified in continental USA in a variety of geology formations. Bedded salt can be a satisfactory medium for a repository, but certain other rock types, notably granite and possibly shale, could offer even greater long-term advantages. Irrespective of the time scale, adopted for reprocessing, two geological demonstration facilities in different media should be completed". (Emphasis by Bethe). The wastes must be solidified, then the solid wastes should be fused with borosilicate glass and put in stell cylindres. It is hard to imagine how the radioactive material could get out into environment from the repository at the depth of $500 \mathrm{~m}$ below the ground after such treatment or how the terrorists could penetrate there.

In some other countries (France, Russia) the decisions about waste disposal are close to recommendations, presented in the Report, although in USA the final decision about waste depository is not taken till now. It must be mentioned, that in recent years the proposal of transmutation by accelerators of radioactive transuranium elements into nonradioactive ones is under discussion and corresponding experiments are under way. Bethe was strongly interested in this proposal and supported the construction of accelerator for this purpose.

In discussion of the problem of radioactivity release by nuclear power plant, Bethe remarks first, that in case of routine operation the radioactive exposure of a person living permanently near the fence of the power plant is negligable in comparison with natural radioactivity. The main danger arises in cases of serious accidents on reactors. The possibility and the consequences of such accidents were studied in 1975 USA Atomic Energy Commision Reactor Safety Study (the results were presented in the so called Rasmussen report) and by American Physical Society's Study Group on Light Water Reactor Safety. Later, in 1986, after the Chernobyl accident a special American panel was formed for its study. Hans Bethe participated in the APS Study Group and in the panel.

The Rasmussen report considered the nuclear reactor core meltdown accident followed by release of radioactivity in the athmosphere, when the containment failed to keep it inside. The report estimated the probability of such an event as 1/200000 per 1000 megawatts electrical reactor year. Of course, this estimation was purely theoretical, be- 
cause no such accident was happend before. The number of fatalities from radiation was estimated as 300. The APS study did not analyse the probability of such accident, but by accounting the delayed cancers, came to much higher estimation of fatalities - about 10000. Even if we take the APS estimation, remarks Berthe [16], the number of fatalities from the accident - about 5 per year for the whole USA - is not very high in comparison with other types of non-nuclear accidents. Naturally, Bethe shared the important conclusions of APS Study Group [17]: 1) the necessity of improval of containment design; 2) mitigation of accident consequences.

The main points of the report of U.S. panel, studyed the Chernobyl accident was presented by Bethe [18]. Bethe stressed, that "Chernobyl-type reactor design is seriously flawed". The reactor is inherently unstable as a physical system: the power of reactor increases with increasing of temperature or the content of steam in the cooling water. This is the main source of this catastrophic accident. (I would like to mention, that this point of view completely concides with mine [5, 6]). The Chernobyl reactor did not have a containment. Therefore, the blow-up of the reactor immediately results in crash of the roof of reactor building and radioactivity was ejected in the athmosphere. Both these defects are absent in U.S. light-water reactors. Moreover, the containments in U.S. reactors are equipped with water sprays, which cool down the steam and radioactive products, condensing them within the containment. The most dangerous fission products - iodine and cesium (in the form of cesium iodide) are highly soluble in the water, ejected by sprays. For these reasons, remarks Bethe, in Three Mile Island accident it was released to the enviroment about one-millionth of the amount of iodine that was ejected into athmosphere at Chernobyl. No amounts of cesium or strontium were detected at Three Mile Island accident. Bethe concludes, that the likelihood of seriously damaging accident is clearly much smaller for U.S. light-water reactors than for the Chernobyl-type. But both the accident at Chernobyl and the less serious one at Three Mile Island indicate "that continued concern for safety is maintained over the full lifetime of U.S. plants" [17] (I add: and over the whole world).

I am thankful to G.Brown for information about Bethe's activity in nuclear energetics and to U.Meissner for his hospitality at the Bonn University, where this paper was written.

This work was supported in part by U.S. CRDF Cooperative Grant Program, Project RUP2-2621-MO-04, RFBR grant 03-02-16209 and the funds from EC to the project "Study of Strongly Interacting Matter" under contract 2004 No R113-CT-2004-506078.

\section{References}

[1] H.A.Bethe, Ann.d.Phys., 3, 133-208 (1929)

[2] H.A.Bethe, Ann.d.Phys., 5, 325-400 (1930)

[3] H.A.Bethe and R.E.Peierls, Proc.Roy.Soc.A, 148, 146 (1935)

[4] R.Rhodes, Dark Sun, Simon and Schuster, N.Y., 1995, p.254 
[5] B.L.Ioffe, Osobo secretnoe zadanie, Novy Mir magazine, No.5, pp.144-155, 1999, No.6, pp.161-172, in Russian; English translation in: Handbook of QCD, ed. by M.Shifman, v.1, pp.18-52, World Scientific, 2001

[6] B.L.Ioffe, Without Retouching, Phasis, 2004 (in Russian).

[7] H.A.Bethe and R.F.Bacher, Rev.Mod.Phys. 8, 193 (1936); H.A.Bethe, Rev.Mod.Phys. 9, 71 (1937)

[8] H.A.Bethe and G.Placzek, Phys.Rev. 57, 1075 A (1940)

[9] H.A.Bethe, Elementary Nuclear theory, John Wiley and sons, N.Y., 1947; H.A.Bethe and P.Morrison, Elementary nuclear theory, 2-nd edition, John Wiley and sons, N.Y., 1956

[10] H.A.Bethe, J.R.Beyster and R.E.Carter, Journal of Nuclear Energy, 3, 207, 273 (1956), 4, 3147 (1957)

[11] H.A.Bethe, Sci.American, 234, 21 (1976)

[12] H.A.Bethe, The Debate on Nuclear Power, in: "Nuclear Power and Its Fuel Cycle", v.7, p.3-17 (IAEA), Vienna, 1977

[13] H.A.Feiveson and T.B.Taylor, The Bull. of the Atomic Scientists, Dec.1976, p.14

[14] B.L.Ioffe and O.V.Shvedov, Atomnaya Energia, 86, 310(1999)

[15] Report to APS by the study group of nuclear fuel cycles and waste management, Rev.Mod.Phys. 50, S1-185, January, 1978, part II

[16] H.A.Bethe, The Bull. of Atomic. Scuientists, Sept. 1975, p.40

[17] F. von Hippel, Bull. of Atomic Scientists, Sept., 1975, p.37

[18] H.A.Bethe, Bull. of Atomic Scientists, Dec. 1986, p.45 